\title{
Interactive comment on "Dissolved Organic Carbon Driven by Rainfall Events from a Semi-arid Catchment during Concentrated Rainfall Season in the Loess Plateau, China" by Linhua Wang et al.
}

\section{Anonymous Referee \#2}

Received and published: 18 March 2019

GENERAL COMMENTS:

This manuscript investigates the dynamic changes in DOC concentration and flux and their relationships to rainfall, runoff characteristics and climatic and soil factors in a semi-arid catchment in Loess Plateau Region, China. To reach the goal, they coupled analyses of runoff water at rainfall event-based frequency, with meteorological data continuously monitoring the rainfall characteristics, air temperature, and soil moisture. Their results showed higher DOC export with low DOC concentration, highlighted that DOC export was influenced by the interaction of hydrological and carbon biogeochemical processes. 
In general, this manuscript is solid work and worthwhile to publish although the presented results are not very spectacular. The high frequency sampling of runoff (24 samples per rainfall) well revealed the temporal change in DOC concentration within a typical event as they showed in four selected events. However, the author should consider re-evaluate the data and re-organize the writing since the event-based analysis is not well discussed. In my opinion, it will be a good contribution biogeochemistry modelers if author delve into individual rainfall event and give information that clearly linking DOC export to rainfall and runoff characteristics.

\section{MAJOR COMMENTS:}

1. Introduction

(1) L43-50: these piled data didn't give a clear background on DOC export. They should be re-organized and present in term of different catchment characteristics. For example, does DOC export differ in area receiving different annual precipitation, or area with different land use, or catchment size and topography.

(2) The knowledge gap is not well stated. I believe the event-based analysis has been done in other region and what kind of information it can provide compare to traditional daily/monthly monitoring? Why do you think you need to conduct event-based analysis in this specific semi-arid area?

\section{Materials and Methods}

Be more specific about the experiment duration. How long/how many rainfall events have you been monitoring and sampling?

\section{Results and Discussion}

(1) The author should either consider combining the result and discussion sections OR separating them clearly in the writing. There are multiple places that the results been re-stated in discussion or discussed the result right after without citation.

Printer-friendly version

Discussion paper 
e.g. L181-L183 should be in discussion section. L196-L197 discussed the result without citation and should be in discussion section. L223-L228 should be in discussion section. L267-269 should be in results section. L274-276 should be in results section. Section 4.2 (L300-L327): results about this part (Table 2) wasn't mentioned in results section.

(2) I'm confused with the way you separate the rainfall events into 4 groups. In Figure 3 you stated in $x$-axis was rainfall intensity, but the unit was $\mathrm{mm}$, not $\mathrm{mm} / \mathrm{h}$. Why do you define rainfall intensity based on accumulated rainfall depth? In the Yang et al. (2018) paper you referred, they denoted the rainfall replenishment in $\mathrm{mm}$ to effectively recharge the soil water. I don't think this is the classification you should use here. My recommendation would be to directly calculate the rainfall density for each individual rainfall event.

(3) The major finding you stated was higher DOC export with low DOC concentration. I have several questions about this finding: In Figure 4, you stated DOC concentration depressed with increased discharge for greater intensity. How are you sure since you only have 5 points with $\mathrm{r} 2$ value of 0.38 . Is this correlation significant? In Figure 5, DOC do show positive relationship with discharge within individual event, how do you explain this contrary?

\section{SPECIFIC COMMENTS:}

L32: insert a summary sentence before "For instance, high DOC...". The following statements come from nowhere and it's confusing.

L104: give the time period for average annual temperature and precipitation. Is 535 $\mathrm{mm}$ only coming from rainfall or also including other type of precipitation?

L112: state specific land alteration in "represent an area with altered land use that has..."

L126-L130: the part "In addition, the aim of hydrological. .." should be stated before

Printer-friendly version

Discussion paper
Interactive

comment 
you introduce the meteorological station, and also should be condensed.

L133: "microbiologically biodegrade" to "microbially degrade".

L138-L140: give CV of procedure accuracy.

L149-L156: this section should be in laboratory analysis or an independent section rather in data analysis.

L166: "in June to September" to "in between June and September".

L186: I suggest to open this paragraph with sentence "In general, runoff discharge tended to follow the pattern of rainfall amount in the study catchment."

L189: where did the value " $34.70 \mathrm{mg} \mathrm{L-1"} \mathrm{come} \mathrm{from?} \mathrm{I} \mathrm{didn't} \mathrm{see} \mathrm{this} \mathrm{value} \mathrm{in} \mathrm{Figure}$ 2 or Figure 5.

L191: "DOC concentration were less variable during June to September", less compare to what?

\section{FIGURES:}

Figure 3: see previous comments about the grouping.

Figure 4: Is the second figure necessary? DOC flux is calculated based on discharge. Why present a variable that is highly dependent on the other variable?

Figure 5: explain in result section why did you choose these four events? Do they show different rainfall intensity? Axis of DOC concentration could be in the same scale.

Figure 6: Axis of DOC concentration could be in the same scale.

Figure 7: my recommendation is to compare discharge with rainfall intensity. 2019. 